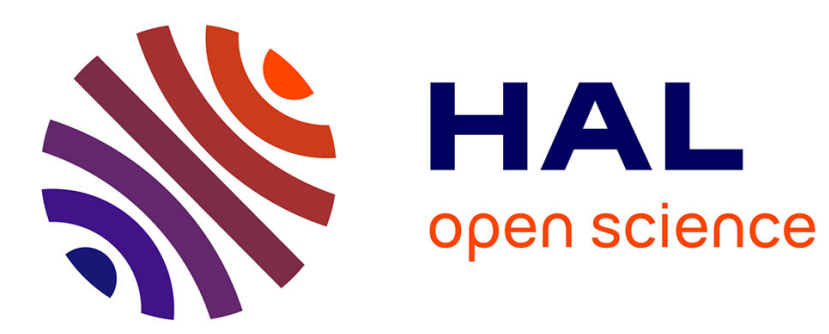

\title{
La circulación del derecho indiano entre los Mayas: Escritura, oralidad y orden simbólico en Yucatán, siglo XVI \\ Caroline Cunill
}

\section{- To cite this version:}

Caroline Cunill. La circulación del derecho indiano entre los Mayas: Escritura, oralidad y orden simbólico en Yucatán, siglo XVI. Jahrbuch für Geschichte Lateinamerikas - Anuario de Historia de America Latina, 2015, 52 (1), 10.7767/jbla-2015-0103 . hal-02416146

HAL Id: hal-02416146

https://hal-univ-lemans.archives-ouvertes.fr/hal-02416146

Submitted on 17 Dec 2019

HAL is a multi-disciplinary open access archive for the deposit and dissemination of scientific research documents, whether they are published or not. The documents may come from teaching and research institutions in France or abroad, or from public or private research centers.
L'archive ouverte pluridisciplinaire HAL, est destinée au dépôt et à la diffusion de documents scientifiques de niveau recherche, publiés ou non, émanant des établissements d'enseignement et de recherche français ou étrangers, des laboratoires publics ou privés. 


\title{
JAHRBUCH FÜR GESCHICHTE LATEINAMERIKAS
}

\author{
ANUARIO DE HISTORIA \\ DE AMÉRICA LATINA
}

BAND 52

2015

BÖHLAU VERLAG KÖLN WEIMAR WIEN 


\section{Inhalt}

Benedetta Albani, Samuel Barbosa, Thomas Duve, Introducción ... . 9

Caroline Cunill, La circulación del derecho indiano entre los Mayas:

Escritura, oralidad y orden simbólico en Yucatán, siglo XVI . . . 15

Nelson Fernando González, Correos y comunicación escrita

en la América colonial: esquemas de distribución de la

correspondencia oficial (1514-1768)

Gustavo César Machado Cabral, Os senhorios na América

Portuguesa: o sistema de capitanias hereditárias e a prática

da jurisdição senhorial (séculos XVI a XVIII)

Rafael Gaune y Verónica Undurraga, El Perdón como espacio

normativo. Circulación, mediación y traducción de discursos

religiosos entre Roma y Santiago, Siglo XVII

Nuno Camarinhas, Administração da Justiça em espaços coloniais. A experiência imperial portuguesa e os seus juízes, na époc moderna ................................ 10

Rafael Diego-Fernández Sotelo, El régimen de intendencias en el marco de las monarquías hispanas

Magdalena Candioti, Regulando el fin de la esclavitud. Diálogos, innovaciones y disputas jurídicas en las nuevas repúblicas sudamericanas 1810-1830.

Monica Duarte Dantas, Da Luisiana para o Brasil:

Edward Livingston e o primeiro movimento codificador no Império (o Código Criminal de 1830 e o Código de Processo Criminal de 1832)

Luís Pedroso de Lima Cabral de Oliveira, "Quem sabe o que é um advogado"? A resposta de Luís Manuel Júlio Frederico Gonçalves às tentativas de reforma dos provisionários goeses em 1869 


\title{
La circulación del derecho indiano entre los Mayas: Escritura, oralidad y orden simbólico en Yucatán, siglo XVI'
}

\author{
por Caroline Cunill
}

Abstract. - Scholars have studied how the institutions of the Spanish Empire were implemented, have functioned and have evolved in America from the Sixteenth to the Nineteenth Century. Nevertheless, those structures only made sense because they were known, used, and eventually manipulated by the historical actors. Consequently, the issue of the circulation of law is instrumental in the understanding of the institutional and political functioning of the Spanish Monarchy. This article focuses on the Maya of the province of Yucatan and its objective is to highlight who could be willing that this sector of the colonial society would know the legislation (Derecho Indiano), and what kind of instruments were used in order to achieve this objective in the Sixteenth Century. The study will take into account the role played by the written, oral, and symbolic culture in the circulation of law among the Maya through the writing, the translation, the printing, and the conservation of legal documents, as well as through the proclamations made by public criers, the Franciscan missionaries' sermons, and the exemplary punishments. One of our hypotheses is that royal agents, the Clergy, the Spaniards, and the Maya themselves were all conscious of the central role played by the circulation of legal culture in the relations of power, so that they struggled to maintain some control on this kind of information throughout the Sixteenth Century.

1 Parte del presente trabajo fue presentado en el simposio "La formación de espacios jurídicos (siglos XVI-XIX): actores, artefactos e ideas" organizado por Benedetta Albani, Samuel Barbosa y Thomas Duve, que tuvo lugar en el congreso del AHILA, Berlín, septiembre 2014. Agradezco a los organizadores y a los participantes por sus sugerencias y comentarios. 


\section{Resumen}

Hasta la fecha de hoy, se ha estudiado en detalle cómo nacieron, se desarrollaron y evolucionaron las instituciones del Imperio español. Sin embargo, aquellas estructuras sólo tuvieron sentido en la medida en que fueron conocidas, utilizadas y, eventualmente, alteradas por los actores históricos. En esta perspectiva, la cuestión de la circulación del derecho se vuelve instrumental para entender cabalmente el funcionamiento político de la Monarquía hispana. El presente artículo se centra en los mayas del Yucatán y pretende esclarecer quiénes fueron interesados en que este sector de la población colonial conociera el derecho indiano y cuáles fueron las herramientas empleadas para lograr aquel objetivo en el siglo XVI. El estudio toma en cuenta el papel desempeñado por la cultura tanto escrita - con la impresión, las copias manuscritas y la conservación de textos legales en archivos -, como oral y simbólica - a través de pregones públicos, de sermones o de castigos ejemplares - en la circulación del derecho entre los mayas. Una de las hipótesis que planteamos es que los representantes de la Corona, los religiosos, los colonos españoles y los mismos mayas lucharon entre sí por mantener cierto monopolio sobre la información legal en el Yucatán del siglo XVI.

\section{Introducción}

Según François-Xavier Guerra, para comprender el funcionamiento de un sistema político no sólo es necesario analizar las instituciones y las leyes, sino también identificar a los actores y estudiar tanto los fundamentos de su poder, como los medios de acción que usaban y los modelos culturales que compartían. ${ }^{2} \mathrm{Al}$ plantear la cuestión de la "formación de espacios jurídicos en Iberoamérica", el simposio convocado por el Max Planck Institute for European Legal Studies se inscribe en esta perspectiva, puesto que nos invita a considerar el derecho en su dimensión dinámica, esto es, a analizar los procesos históricos que condujeron a la conformación de comunidades de actores que compartían una cultura jurídica común en un espacio trasnacional y hasta transatlántico en el caso que nos ocupa. Y es que, como explica Samuel Barbossa, "la formación de espacios jurídicos depende de la producción de conocimiento y de su inscripción material", de modo que "la

2 François-Xavier Guerra, "L'Etat et les communautés. Comment inventer un Empire?": Serge Gruzinski/Nathan Wachtel (eds.), Le Nouveau Monde. Mondes nouveaux. L'expérience américaine (Paris 1996), pp. 351-364, aquí: p. 353. 
relación mutuamente constitutiva entre derecho y espacio está condicionada por la circulación de la información". ${ }^{3}$ En este sentido, los conceptos de circulación, transferencia y re-significación también resultan fundamentales, al permitir romper el "paradigma estatal-nacional" que ha dominado la historia del derecho desde el siglo XIX. ${ }^{4}$

Bien es cierto que, desde hace algunos años, investigadores como Bartolomé Yun Casalilla, Serge Gruzinski o Christine Daniels y Michael Kennedy han recurrido a los conceptos de "globalización", "historias cruzadas" e "Imperios negociados" para poner de manifiesto el papel desempeñado por la circulación de las personas y de la información en la construcción y el funcionamiento del Imperio ibérico. ${ }^{5}$ Aquellos estudios han contribuido en relativizar el papel del "centro" en la elaboración de un orden normativo, puesto que el funcionamiento de las instituciones dependía, en buena medida, de los informes que procedían de las "periferias", sin contar con la independencia de que gozaban los jueces locales en el proceso legal. ${ }^{6} \mathrm{Arndt}$ Brendecke ha analizado, por ejemplo, los mecanismos de recolección de la información sobre el Nuevo Mundo y su tratamiento en los máximos órganos del gobierno hispano, especialmente en el Real Consejo de Indias, con el fin de mostrar el vínculo entre saber y dominio colonial. ${ }^{7}$ Finalmente, pese al reciente desarrollo de una literatura científica centrada en el papel desempeñado por los indígenas como negociadores dentro del sistema polí-

3 Samuel Barbossa, "Comentarios introductorios al simposio formación de espacios jurídicos en Iberoamérica", 2014, pp. 7-8: "Além disso, a formação dos espaços jurídicos depende da produção de conhecimento e de sua inscrição material [...]. Por fim, a relação mutuamente constitutiva entre direito e espaço é condicionada pela circulação de informação".

4 Véanse Thomas Duve, "European Legal History - Global Perspectives": Max Planck Institute for European Legal History Research Paper Series (Frankfurt am Main 2013), en linea: http://ssrn.com/abstract=2292666 [13-06-2015]; y "Comentarios introductorios al simposio formación de espacios jurídicos en Iberoamérica", 2014, p. 2.

5 Christine Daniels/Michael V. Kennedy (eds.), Negotiated Empires. Centers and Peripheries in the Americas, 1500-1820 (London 2002). Bartolomé Yun Casalilla (ed.), Las redes del Imperio. Élites sociales en la articulación de la Monarquía hispánica, 1492-1714 (Madrid 2009). Serge Gruzinski, "Passeurs y élites „católicas" en las Cuatro Partes del Mundo. Los inicios ibéricos de la mundialización (1580-1640)": Scarlett O'Phelan Godoy/ Carmen Salazar Soler (eds.), Passeurs, Mediadores culturales y agentes de la primera globalización en el Mundo Ibérico. Siglos XVI-XIX (Lima 2005), pp. 13-29.

6 Véase Benedetta Albani, "Comentarios introductorios al simposio formación de espacios jurídicos en Iberoamérica", p. 5.

7 Arndt Brendecke, Imperio e información. Funciones del saber en el dominio colonial español (Madrid 2012). Véase también Jesús Bustamante, "El conocimiento como necesidad de Estado. Las encuestas oficiales sobre Nueva España durante el reinado de Carlos V": Revista de Indias 60:218 (2000), pp. 33-57. 
esta cultura entre los indígenas; cuáles fueron las medidas implementadas y las herramientas (materiales/humanas) utilizadas para llevar a cabo tal objetivo; qué papel ocuparon la escritura, la oralidad y el orden simbólico en este proceso; y, finalmente, en qué medida la población maya participó de forma consciente y activa en la adquisición y en la co-creación de la cultura jurídica colonial en formación.

\section{Fomentar una cultura jurídica entre los indígenas, ¿una política real?}

Desde los inicios de la colonización, la comunicación con los indígenas representó un reto político para la Corona española. Así, en 1509 el rey Fernando el Católico prohibió que ningún oficial obstaculizara el envío a la metrópoli de informes que tenían que ver con la población autóctona. ${ }^{2} \mathrm{En}$ su memorial de 1516, fray Bartolomé de Las Casas también planteó la necesidad de que algunos representantes del monarca español hablaran con los caciques y les explicaran que eran vasallos del rey y podían esperar de él justicia y protección. ${ }^{13}$ Por lo tanto, una de las misiones de los frailes Jerónimos consistió en decir a los caciques de las Islas "cómo de su parte se han dado acá ante Nos [el monarca] ciertas peticiones de muchos y grandes agravios que dizque han recibido de los pobladores [...] y cómo Nos somos justos Reyes y Señores suyos y que no hemos de consentir ni dar lugar que, pues ellos son nuestros súbditos y cristianos, sean maltratados como no deben". ${ }^{14}$ Según las Instrucciones, los Jerónimos estarían acompañados por "algunos religiosos de los dominicos y franciscanos", que radicaban en las Islas, para que éstos sirvieran como intérpretes y tradujeran este mensaje oficial a los indígenas. ${ }^{15}$ En 1543 Carlos I pidió a fray Juan de Zumárraga, fray Domingo de Betanzos, fray Juan de la Magdalena y a otros religiosos

\footnotetext{
${ }^{12}$ Lewis Hanke, La lucha por la justicia en la conquista de América (Buenos Aires 1949), pp. 29-30.

${ }^{13}$ Memorial de fray Bartolomé de las Casas, 1516, en la Colección de documentos inéditos relativos al descubrimiento, conquista y organización de las antiguas posesiones españolas en América y Oceania, vol. VII (Madrid 1867), pp. 20-21. Publicado también en fray Bartolomé de las Casas, Opúsculos, cartas y memoriales, vol. CX (edición de Juan Pérez de Tudela Bueso, Madrid 1958), p. 8 y en Cartas y memoriales, vol. XIII (edición de Paulino Castañeda Delgado, Madrid 1995), p. 26.

${ }^{14}$ Instrucciones a los frailes jerónimos, 1516, en la Colección, vol. XI (nota 13), p. 260.

${ }^{15}$ Ibidem.
} 
tico del Imperio ibérico y a la constatación de que éstos poseían profundos conocimientos jurídicos, hasta la fecha de hoy se ha prestado relativamente poca atención a las condiciones materiales en que se realizó la circulación del derecho entre la población autóctona de América. ${ }^{8}$

Por lo general, la historiografía americanista se ha enfocado en los conocimientos jurídicos de la élite española y criolla adquiridos a través de la cultura libresca y de las carreras universitarias. ${ }^{9}$ Sin embargo, como bien apunta Tamar Herzog, la cultura legal no se puede constreñir al "conocimiento adquirido por los letrados durante sus estudios universitarios", sino que también tiene que abarcar las prácticas realizadas en "el trabajo cotidiano del sistema jurídico", esto es, la "resolución de conflictos" a la que se dedicaban los jueces no-letrados con la ayuda de agentes como los escribanos, los procuradores o los relatores. ${ }^{10}$ Esta comunidad aún se ensancha de tomarse en cuenta el papel de la oralidad, las fiestas, los castigos ejemplares y otros actos públicos en la creación, la reproducción e la imposición de un orden normativo. " No cabe duda de que los indígenas también participaron de aquella cultura jurídica colonial y nos preguntaremos, por lo tanto, si existió una voluntad política, por parte de la Corona española, por fomentar

8 Véanse, entre otros, Brian P. Owensby, Empire of Law and Indian Justice in Colonial Mexico (Stanford 2008). Ethelia Ruiz Medrano/Susan Kellogg (eds.), Negotiation within Domination. New Spain's Indian Pueblos Confront the Spanish State (Boulder 2010). Ana de Zaballa Beascoechea (ed.), Los indios, el Derecho Canónico y la justicia eclesiástica en la América virreinal (Madrid 2011). Yanna Yannakakis, "Indigenous People and Legal Culture in Spanish America": History Compass 11:4 (2013), pp. 931-947. Caroline Cunill, "La negociación indígena en el Imperio ibérico. Aportes a su discusión metodológica": Colonial Latin American Review 21:3 (2012), pp. 391-412.

9 Consúltense Javier Barrientos Grandón, La cultura jurídica en Nueva España. Sobre la concepción de la tradición jurídica europea en el virreinato (México 1993). Aurelia Vargas Valencia, Las Instituciones de Justiniano en Nueva España (México 2001). Mónica Quijada/Jesús Bustamante (eds.), Élites intelectuales y modelos colectivos. Mundos ibéricos, siglos XVI-XVII (Madrid 2002). Carlos Alberto González/Enriqueta Vila Vilar (eds.), Grafias del imaginario. Representaciones culturales en España y América, siglos XVI-XVIII (México 2003).

${ }^{10}$ Tamar Herzog, "Sobre la cultura jurídica en la América colonial (siglos XVI-XVII)": Anuario de Historia del Derecho Español 65 (1995), pp. 903-911. Véanse también Alejandro Madrazo, "Estado de derecho y cultura jurídica en México": Isonomia 17 (009), pp. 203-238. Lawrence M. Friedman, The Legal System. A Social Science Perspective (New York 1975). Paul W. Kahn, The Cultural Study of Law. Reconstructing Legal Scholarship (Chicago 1999).

"Sobre estos aspectos, véanse Solange Alberro, "Las Cuatro Partes del Mundo en las fiestas virreinales peruanas y novohispanas": Godoy/Soler (eds.), Passeurs (nota 5), pp.147161. Patricia Seed, Ceremonies of Possession in Europe's Conquest of the New World. 1492 1640 (Cambridge 1995). John Smolenski/Thomas J. Humphrey (eds.), New World Orders. Violence, Sanction, and Authority in the Colonial Americas (Philadelphia 2005). 
que parecieran "ante reyes y otras autoridades [...] para confederarlos en perpetua amistad con el rey y sus súbditos". 16

Queda claro, por consiguiente, que la Corona española era consciente de que fomentar la creación de una cultura jurídica entre los indígenas era una de las condiciones básicas para garantizar la existencia efectiva de la jurisdicción real sobre aquel sector de la población colonial. Y es que algunos actores históricos, como fray Bartolomé de las Casas, insistieron en que la ausencia de tal conciencia entre los indios dejaba el campo libre a que cualquiera usurpara la autoridad real y cometiera todo tipo de abusos. El dominico citaba el caso del colono español Baltasar Guerra, quien pretendía ser el hermano del rey y que ejercía así jurisdicción sobre los indios que formaban parte de su encomienda. ${ }^{17}$ Del mismo modo, en 1545 el visitador Tello de Sandoval informó el Consejo de Indias de que no había justicia fuera de las veinticinco leguas que rodeaban a la ciudad de México, puesto que, más allá de aquel territorio, "ni los indios se saben quejar ni a quien, ni el remedio tienen" y había lugares donde los naturales tenían "por reyes a los encomenderos y señores de los pueblos y no conocían su verdadero rey". ${ }^{18}$

A partir de la década de 1540 también se impuso la idea de que era menester conocer las leyes para acatarlas y que no se podía castigar a quien no fuese suficientemente instruido de las normas vigentes. En consecuencia, se estableció que hasta que los indígenas tuvieran "noticia de nuestras leyes", éstas "no les obligan y que para castigarlos por ellas es necesario que se les publiquen, a lo menos las comunes en que suelen comúnmente incurrir". De este modo, se mandó pregonar a los indigenas "las tales leyes por intérpretes para que vengan a su noticia, y que antes que se les notifique no se castigue ninguno a pena de muerte". ${ }^{19}$ Cabe recordar, en efecto, que en 1542 la Corona española proveyó que las Leyes Nuevas fueran traducidas a las principales lenguas autóctonas y que fueran impresas y distribuidas entre la población indígena. En la cláusula final se mandó que "esta nuestra carta sea impresa en molde y se envíe a todas las nuestras Indias a los religiosos que en ellas entienden en la instrucción de los dichos indios,

\footnotetext{
${ }^{16}$ Silvio Zavala, Por la senda hispana de la libertad (2. ed., México 1992), p. 121.

${ }^{17}$ André Saint-Lu, Las Casas indigéniste. Etudes sur la vie et l'ouvre du défenseur des Indiens (Paris 1982), pp. 104-116.

${ }^{18}$ Carta del visitador Tello de Sandoval al rey, México, 9 de septiembre de 1545, citado por Pilar Arregui Zamorano, La Audiencia de México según los visitadores de los siglos XVI y XVII (México 1984), p. 240.

${ }^{19}$ Minuta inédita (ca. 1540), citada por Manuel Olmedo Jiménez, Jerónimo de Loaysa. O.P., pacificador de españoles y protector de indios (Granada 1990), p. 142.
} 
a los cuales encargamos que allá las hagan traducir en lengua india para que mejor lo entiendan y sepan lo proveído". 20

Asegurarse que los indios supieran que los reyes españoles hacían lo posible para que fueran bien tratados representó una preocupación constante para la Monarquía. Así lo demuestra, por ejemplo, una consulta de 1581 donde Felipe II ordenó a sus consejeros que "apretasen mucho todo lo que a esto tocase de manera que hallasen todos remedio con efecto y [los indios] entendiesen que tengo yo el cuidado que es razón para que sean bien tratados y se les haga justicia". ${ }^{21}$ Pero la lejanía y la diversidad lingüística del continente americano hicieron necesaria la participación de intermediarios entre la Corona y los indígenas, papel que fue confiado a las órdenes mendicantes en un primer momento. ${ }^{22}$ Así, una real cédula de 1544 volvió a insistir en que a los religiosos incumbía la misión de dar "a entender a los naturales [las nuevas ordenanzas] y procur[ar] la observación de ellas". ${ }^{23}$ También resulta revelador el comentario del español Jerónimo López, según el cual había aumentado la "insolencia de los indios" por haberse "publicado y predicado y aclarado en los púlpitos" las Leyes Nuevas. ${ }^{24}$ Esto indica que los religiosos no se contentaron con fungir de intérpretes en el sentido estrictamente lingüístico, sino que también hicieron la exégesis de los textos legales. Es sabido, además, que en muchas ocasiones los frailes hasta asesoraron a los indios en sus batallas jurídicas. ${ }^{25}$

${ }^{20}$ Leyes Nuevas de 1542-1543, transcripción y notas de Antonio Muro Orejón (Sevilla 1945), pp. 820-827.

${ }^{21}$ Consulta sobre las cosas que, según memorial de fray Pedro Mártir, provincial de la Orden de Santo Domingo, conviene remediar en Indias acerca del buen gobierno y trato de los indios, 6 fols., Madrid, 24 de abril de 1581, citado por Antonia Heredia Herrera, Catálogo de las consultas del Consejo de Indias, vol. I (Madrid 1972), p. 317. Archivo General de Indias (en adelante AGI), Santa Fe 1, N. 28.

${ }^{22}$ Los religiosos eran conocedores de las lenguas autóctonas, estaban bien distribuidos por el territorio y ocupaban una destacada posición en la instrucción de los indios. Para el caso yucateco, véase William F. Hanks, Converting Words. Maya in the Age of the Cross (Berkeley 2010).

${ }^{23}$ Real cédula al obispo de Chiapas, Valladolid, 13 de febrero de 1544, citada por Olmedo Jiménez, Jerónimo (nota 19), p. 135.

${ }^{24}$ Carta de Jerónimo López al Emperador, México, 25 de febrero de 1545, en Francisco del Paso y Troncoso, Epistolario de Nueva España. 1505-1818, vol. IV (México 1939), p. 165.

${ }^{25}$ Sobre el papel de los religiosos como representantes legales de los indígenas en pleitos que éstos sustentaron en las Audiencias americanas hasta por lo menos la década de los 1560, véanse Ethelia Ruiz Medrano, "Poder e Iglesia en Nueva España. La disputa del diezmo": José Román Gutiérrez/Enrique Martínez Ruiz/Jaime González Rodríguez (eds.), Felipe II y el oficio de rey. La fragua de un imperio (Madrid 2002), pp. 835-867. Jaime Muñoz Lacueva/Caroline Cunill, "La negociación indígena frente al afianzamiento econó- 
El papel de mediación que la Corona española encargó a los religiosos aparece, por ejemplo, en las ordenanzas de Granada de1526, donde se les mandó procurar que los indios fueran bien tratados y que "si lo contrario se hiciere por cualquier persona de cualquier calidad o condición que sea, tengan muy gran cuidado y solicitud de Nos avisar luego en pudiendo particularmente de ello". Uno de los principales encargos de los obispos protectores consistió, asimismo, en hacer "pesquisas e informaciones" acerca del tratamiento que recibían los naturales y en comunicar el resultado de las mismas a las Reales Audiencias y al Consejo de Indias. La misión informativa de los prelados fue la única que no sufrió restricciones en las nuevas instrucciones que éstos recibieron en 1530. Ésta incluso se vio reforzada por la cédula real del 28 de enero de 1533 por la que los obispos se habían de convertir en informantes confidenciales del monarca en asuntos de gobierno. ${ }^{26}$ En 1540 los obispos de Antequera, México, Michoacán y Guatemala pidieron al rey de España que les diera acceso directo a las leyes promulgadas a favor de los naturales para que pudieran solicitar su aplicación sistemática ante las autoridades del Nuevo Mundo. Lamentaban que, si bien la Corona había proveído muchas cédulas y provisiones "para el pro y el bien espiritual y temporal de estas tierras e Iglesia nueva de ella, por otras ocupaciones se olvidan y no se cumplen". Por consiguiente, suplicaban que estos documentos fuesen enviados "originalmente a los prelados porque tanto bien y merced y gracia de Dios y de Vuestra Majestad [...] no se olvide, enfríe ni pierda ni impida el debido efecto de ellas por algún descuido u otras ocupaciones". 27

El rol de divulgación de la cultura legal hispana que desempeñaron los religiosos en América también queda plasmado no sólo en los diccionarios bilingües de los siglos XVI y XVII, sino también en la inclusión de modelos testamentarios en los confesionarios de la misma época. Miguel León-Portilla identificó, por ejemplo, una serie de términos en relación con la institución testamentaria en el Vocabulario de fray Alonso de Molina de

mico hispano. La defensa de las minas de alumbre de Meztitlán en el siglo XVI": Manuela Cristina Garcia Bernal/Sandra Olivero Guidobono (eds.), El municipio indiano. Relaciones interétnicas, sociales y económicas. Homenaje a Luis Navarro García (Sevilla 2009), pp. $39-58$.

${ }^{26}$ Juan Friede, "Los orígenes de la protectoría de indios en el Nuevo Reino de Granada en la primera mitad del siglo XVI": [s.n.] (ed.), Miscelánea de Estudios dedicados al Dr. Fernando Ortiz por sus discípulos, colegas y amigos (La Habana 1956), pp. 643-655, aquí: p. 651.

${ }^{27}$ Carta de los obispos de Nueva España sobre las cosas que era necesario proveer para el buen gobierno de sus iglesias, México, 1940, en Paso y Troncoso, Epistolario (nota 24), pp. 8-18. 
1555 , lo que pone de manifiesto el deseo de Molina de brindar a los indígenas "un modo adecuado de expresarse en materia testamentaria". Por otro lado, el investigador llama la atención sobre la presencia de "esquemas para la formulación de testamentos" en el Confesionario mayor en lengua mexicana y castellana de Molina (1565) y en el Camino del cielo en lengua mexicana de fray Martín de León (1611). Ambos textos iban acompañados de recomendaciones dirigidas a los escribanos indígenas para que respetaran las normas que habían de seguirse en estas circunstancias. Para León-Portilla, no queda duda de que aquellos modelos fueron utilizados por los autores del corpus de 150 testamentos en lengua náhuatl que él mismo localizó en el Archivo General de la Nación, en la Biblioteca Nacional de México y en una colección particular. ${ }^{28}$

No obstante, la existencia de un auténtico monopolio de la comunicación entre los religiosos y los indígenas fue denunciada, a su vez, por las autoridades civiles desde fechas tempranas. A este respecto, conviene citar el comentario del oidor de la Real Audiencia de los Confines, Tomás López Medel, quien afirmó en 1550 que los frailes eran como "reyes" en los pueblos de indios. ${ }^{29}$ De hecho, no cabe duda de que el anhelo por comunicar con los indígenas y ganarse así su apoyo generó varios conflictos entre distintos sectores de la sociedad colonial a lo largo del siglo XVI. Se puede mencionar el caso del primer obispo de Nueva España, fray Juan de Zumárraga, quien recurrió al sermón para recoger testimonios indígenas en una información que denunciaba las exacciones de los oidores de la primera Audiencia de México. Pero aquellas autoridades pronto reaccionaron y mandaron pregonar la prohibición de que ningún indio tratara con el obispo. Por otro lado, hicieron circular entre los naturales un libelo difamatorio en contra del obispo y de los religiosos..$^{30}$ En este contexto de tensión, la Corona española pronto comprendió el interés de prescindir de intermediarios para comunicar con los indígenas. Así, pues, a partir de los 1550 se esforzó para que los indios pudiesen acceder a un amplio abanico de información legal de manera independiente, para eliminar posibles monopolios

${ }^{28}$ Miguel León-Portilla, "El libro inédito de los testamentos indígenas de Culhuacán. Su significación como testimonio histórico": Estudios de Cultura Náhuatl 12 (1976), pp. 11-31.

${ }^{29}$ Carta de Tomás López a los reyes de Bohemia, Guatemala, 9 de junio de 1551, en Berta Ares Queija, Tomás López Medel. Trayectoria de un clérigo-oidor ante el Nuevo Mundo (Guadalajara 1993), p. 285. Algunos historiadores han insistido en la influencia e, incluso, la coerción que ejercían los religiosos en las comunidades mayas de Yucatán. Sobre este tema, véase Inga Clendinnen, "Disciplining the Indians. Franciscan Ideology and Missionary Violence in Sixteenth Century Yucatan", Past and Present 94 (1982), pp. $27-48$.

30 Joaquín García Icazbalceta, Biografia de don fray Juan de Zumárraga, primer obispo varanhicnn do Mórirn (Madrid 1979) nn 57-56 
de comunicación y consolidar su propia jurisdicción sobre la población autóctona. ${ }^{31}$

En 1551 Felipe II permitió que los naturales pudiesen viajar a España en calidad de procuradores, ya que impedírselo perjudicaba sus intereses al no poder "informar de cosas que les convienen" y dejar así de "alcanzar cosas que les es muy necesarias". Por otro lado, una cédula real de 1556 dispuso que, cuando se tomara residencia a un oficial español, se diera avisar de ello a los indios para que pudieran pedir justicia. ${ }^{32}$ Además, la tarea de brindar información a las autoridades reales sobre la condición indígena y de comunicar a la población autóctona las disposiciones reales que la beneficiaban fue confiada a un nuevo cuerpo de funcionarios reales, los defensores de indios. ${ }^{33}$ Un primer antecedente de esta nueva política se desprende de una cédula de 1550, en la que se mandó pregonar en los pueblos de indios no sólo la ley de liberación de los esclavos indígenas, sino también el nombre del procurador designado para asesor y representar a los beneficiarios de la misma. ${ }^{34} \mathrm{En}$ sus instrucciones para defensores de indios de 1552 el oidor Tomás López Medel ordenó que, si fuera necesario ir a los pueblos de indios para informarse, el defensor podía hacerlo. ${ }^{35} \mathrm{Y}$ en las de 1557 estipuló que este oficial procurase "darse a conocer a los dichos indios para que acud[ier]an a él con sus agravios y quejas". ${ }^{36}$ Estos intermediarios, a los que habría que sumar a los abogados y los procuradores privados, ya fueran españoles o indígenas, facilitaron la asimilación del derecho indiano

${ }^{31}$ Sobre este aspecto, véase Brian P. Owensby, "Pacto entre rey lejano y súbditos indígenas. Justicia, legalidad y política en Nueva España, siglo XVII": Historia Mexicana 61:1 (2011), pp. 59-106.

${ }^{32}$ Cédula que manda que los indios puedan enviar a estos reinos procuradores indios por tres años, Lérida, 8 de agosto de 1551 y cédula que manda que cuando se publicare residencia contra alguna persona sea de manera que venga a noticia de los indios para que puedan pedir su justicia, 1556, en Diego de Encinas, Cedulario Indiano vol. IV (Madrid 1946), fols. 358-359.

${ }^{33}$ Sobre los defensores de indios, véanse Woodrow Borah, El Juzgado General de Indios de la Nueva España (México 1985). Charles Cutter, The Protector de Indios in Colonial New Mexico. 1659-1821 (Albuquerque 1986). Carmen Ruigómez Gómez, Lna política indigenista de los Habsburgo. El Protector de Indios en el Perú (Madrid 1988). Caroline Cunill, Los defensores de indios de Yucatán y el acceso de los mayas a la justicia colonial. 1540-1600 (Mérida 2012).

${ }^{34}$ Silvio Zavala, Los esclavos indios en Nueva España (2. ed., México 1981), pp. 120 140.

${ }^{35}$ Caroline Cunill, "Tomás López Medel y sus instrucciones para defensores de indios. Una propuesta innovadora": Anuario de Estudios Americanos 68:2 (2011), pp. 539-563.

${ }^{36}$ Instrucciones para defensores de indios de Tomás López Medel, Santa Fe, s. f. [ca. 1557], en Ares Queija, Tomás López Medel (nota 29), pp. 387-390. 
por parte de la población autóctona. ${ }^{37} \mathrm{El}$ nombramiento de intérpretes en los juzgados americanos, que empezó a ser sistemático a partir de la década de los 1560, también obedeció al mismo objetivo político, ya que estos oficiales traducían al castellano las peticiones y declaraciones indígenas y transcribían en las lenguas autóctonas las sentencias dadas por las autoridades locales y las principales leyes relativas a la policía cristiana y al buen gobierno. ${ }^{38}$

Sin embargo, los defensores de la causa indígena hasta fueron más allá de ello, al exigir la participación institucionalizada y directa de los indígenas en los circuitos de información para que éstos pudiesen posicionarse en los debates que atañían a sus intereses. En efecto, en un memorial de 1560 fray Bartolomé de Las Casas y fray Domingo de Santo Tomás pidieron al monarca español que se diera un "traslado a los indios de todas las provisiones y cédulas que Su Majestad ha enviado y enviare a estos Reinos para bien y defensa de los naturales de ellos y se cumplan y guarden así las enviadas como las que se enviaren". ${ }^{39}$ Los autores solicitaban, además, la presencia de representantes indígenas en los máximos órganos de gobierno de la Monarquía con el fin de evitar que, en ellos, el punto de vista de la

37 Véanse Yanna Yannakakis, The Art of Being In-between. Native Intermediaries, Indian Identity, and Local Rule in Colonial Oaxaca (Durham 2008). Renzo Honores "Ia asistencia jurídica privada a los señores indígenas ante la Real Audiencia de Lima. 15521570", Ponencia presentada en el Congreso de la LASA, Dallas, 27-29 de marzo de 2003. Disponible en http://lasa.international.pitt.edu/lasa2003/honoresrenzo.pdf [30-06-2015]. Víctor Gayol, "Los gestores de los indios. La relación entre las comunidades litigantes y los juzgados de la real Audiencia a través de la correspondencia de Manuel Salvador Muñoz, indio cacique de Contla, 1788-1803": Historias Revista de la Dirección de Estudios Históricos del Instituto Nacional de Antropología e Historia 69 (2008), pp. 37-55.

38 Véanse Caroline Cunill, "Los intérpretes de Yucatán y la Corona española. Negociación e iniciativas privadas en la fragua del Imperio ibérico, siglo XVI": Colonial Latin American Historical Review 1:4 (2013), pp. 361-380; Idem, "Justicia e interpretación en sociedades plurilingües. El caso de Yucatán en el siglo XVI": Estudios de Historia Novohispana 52 (México, en prensa). Yanna Yannakakis, "Making Law Intelligible. Networks of Translation in Mid-Colonial Oaxaca": Gabriela Ramos/Yanna Yannakakis (eds.), Indigenous Intellectuals. Knowledge, Power, and Colonial Culture in Mexico and the Andes (Durham 2014), pp. 79-106. Martina Schrader-Kniffki/Yanna Yannakakis, "Sin and Crimes. Zapotec-Spanish Translation in Catholic Evangelization and Colonial Law in Oaxaca, New Spain": Otto Zwartjes/Klaus Zimmermann/Martina Schrader-Kniffki (eds.), Missionary Linguistics V. Translation Theories and Practices: Selected Papers from the Seventh International Conference on Missionary Linguistics (Amsterdam 2014). José Carlos de la Puente Luna, "The Many Tongues of the King. Indigenous Language Interpreters and the Making of the Spanish Empire": Colonial Latin American Review 23:2 (2014), pp. 143-170.

${ }^{39}$ Carlos Sempat Assadourian, "Los señores étnicos y los corregidores de indios en la conformación del Estado colonial": Anuario de Estudios Americanos 44 (1987), pp. 325426, aquí: p. 415. 
población autóctona estuviera ausente o distorsionado. Según los dominicos, "todas las veces que se tratare alguna cosa por el Consejo de Su Majestad o sus gobernadores u otros justicias que generalmente toque a toda la república de los indios" se había de hacer "saber a las provincias principales para que envíen sus procuradores que, siendo en pro de su república, se haga con su consentimiento y no siéndolo den razón de ello y sean oídos conforme a derecho"..$^{40} \mathrm{~A}$ este respecto, cabe subrayar que la Corona española había fomentado la autonomía política indígena a nivel local a través de la institución del cabildo indígena y, por lo tanto, la creación de una cultura jurídica hispana entre los gobernantes indígenas, desde fechas tempranas.

Así puede interpretarse tanto el esfuerzo por alfabetizar a la élite indígena, como la formación de los naturales en los elementos básicos del buen gobierno y policía cristiana, tres aspectos estrechamente vinculados. ${ }^{41}$ Como bien recuerda Tamar Herzog, en efecto, en aquella época "la religión formaba parte del derecho, tanto en virtud de su constitución en una fuente independiente de reglas de actuación humana, como mediante el dominio de la noción de 'Justicia", por lo que la teología constituía "una disciplina fundamental para cualquier acto jurídico" y "los escritos sagrados y el dogma cristiano jugaban un papel importante en los tribunales". ${ }^{42}$ No sorprende, por consiguiente, que el oidor Tomás López Medel recomendara la impresión y la distribución en los pueblos de indios de Yucatán de "muchas tablas de grandes letras en que se contengan los diez mandamientos, los artículos de la fe, los mandamientos de la Iglesia y los sacramentos". ${ }^{43}$ Asimismo, el oidor se cuidó de dar instrucciones a los caciques mayas para que supieran cómo regirse, ya que consideraba que no se podía confiarles cargos sin informarles correctamente de sus obligaciones. ${ }^{44}$ En 1583 el visitador Diego García de Palacio también dejó ordenanzas para esclarecer el proceso de elección, las funciones y las obligaciones de los cabildantes

${ }^{40}$ Ibidem, p. 413. Esta petición debe ponerse en relación con la lucha llevada a cabo por fray Bartolomé de las Casas por la institucionalización del cargo de defensor de indios en el Consejo de Indias. Sobre este tema, véase Caroline Cunill, "Fray Bartolomé de las Casas y el oficio de defensor de indios en América y en la Corte española": Nuevos Mundos Mundo Nuevo (2012), en línea: http://nuevomundo.revues.org/63939 [19-06-2015]

${ }^{41}$ Véase Caroline Cunill, "La alfabetización de los mayas yucatecos y sus consecuencias sociales (1545-1580)": Estudios de Cultura Maya 31 (2008), pp. 163-192.

${ }^{42}$ Herzog, "Cultura" (nota 10), p. 909.

${ }^{43}$ Carta de Tomás López Medel a los reyes de Bohemia, Guatemala, 9 de junio de 1550 , en Ares Queija, Tomás López Medel (nota 29), pp. 282-284.

${ }^{44}$ Ibidem. Parte de las ordenanzas de Tomás López Medel para los pueblos de indios de Yucatán están recogidas en Diego López de Cogolludo, Historia de Iucatán, lib. V (Barcelona 2007), cap. 16-19, pp. 423-437. 
indígenas. ${ }^{45}$ Aunque no se localizaron traducciones mayas de este género de textos legales, es probable que tales documentos circularan entre las comunidades de Yucatán. Así lo sugiere la existencia de una versión nahua de las ordenanzas para el buen gobierno de los indios promulgadas por el virrey don Antonio de Mendoza en 1546. Según Susan Kellogg y Barry Sell, numerosas copias manuscritas tanto de este texto, como de otros compendios legales debieron de circular entre los pueblos de indios del centro de México. ${ }^{46}$

\section{El papel de los mayas en la generación, circulación y conservación de documentos legales}

Las disposiciones mencionadas ponen de manifiesto el interés de la Corona española por fomentar la creación de una cultura jurídica entre los indígenas, así como las herramientas humanas, materiales e institucionales que fueron movilizadas para lograr aquel objetivo. Pero los indígenas no fueron pasivos receptores en los procesos de trasplante y circulación de la cultura jurídica colonial, sino que participaron activamente en ellos, pues eran conscientes de que informar, ser informado y conservar información legal era sinónimo de poder. Así, en la Crónica de Chac Xulub Chen de 1562, el cacique Ah Nakuk Pech recordó al oidor Tomás López Medel, quien institucionalizó el oficio de defensor de indios y dejó ordenanzas para el buen gobierno de los pueblos de indios, como el "mensajero de nuestro gran príncipe y rey, el que reina en Castilla, a protegernos de las manos de los españoles". ${ }^{47}$ Este fragmento indica que los mayas de Yucatán valoraron positivamente la labor de quienes se esforzaron por darles a conocer y, al mismo tiempo, por construir una nueva cultura jurídica en América. Además, desde fechas tempranas los mayas hicieron lo posible para conocer no

${ }^{45}$ Ordenanzas que el doctor Palacio manda guardar entre los naturales de las provincias de Yucatán para su buen uso, conservación y aumento, y relevarlos de las cargas y agravios que hasta aquí han padecido, s. f. AGI, Indiferente General 2987. Este texto fue transcrito y analizado por Manuela Cristina García Bernal, "García de Palacio y sus ordenanzas para Yucatán": Temas Americanistas 5 (1985), pp. 1-12.

${ }^{46}$ Susan Kellogg/Barry D. Sell, "We Want to Give Them Laws. Royal Ordinances in a Mid-Sixteenth Century Náhuatl Text”: Estudios de Cultura Náhuatl 27 (1997), pp. 325-367, aquí: p. 333.

${ }^{47}$ Héctor Pérez Martínez, Historia y crónica de Chac-Xulub-Chen (México 1936). Sobre este documento y su autor, véase también Deyanira Dávalos Arellano, "La crónica de Chac Xulub Chen. El discurso y la sumisión del linaje Pech como arma de lucha": Kinkaban 1:1 (2012), pp. 58-63, en línea: http://www.ceicum.org/Datos/2012-1/PDF/2012_1_58-63. Ddf 「10-09-2015]. 
sólo las disposiciones que los amparaban, sino también el discurso legal que les permitiría defender sus intereses con eficacia ante las autoridades coloniales. No sorprende, por consiguiente, que el defensor de indios Francisco Palomino declarara en 1572 que "acudieron a él los indios de los pueblos de los términos de la villa de Valladolid y Campeche de estas provincias a pedirle los hiciese desagraviar" y, de manera general, que "todos los dichos naturales de esta gobernación acuden con sus negocios a esta ciudad de Mérida por residir en ella el gobernador y, para el despacho de ellos, han acudido al dicho Francisco Palomino". ${ }^{48}$

La búsqueda de información legal por parte de los mayas, así como los importantes medios, humanos y materiales que éstos estaban dispuestos a invertir en ello, también queda plasmada en otro acontecimiento. En la década de 1570, el encomendero Rodrigo Fránquez se dedicaba a recorrer los pueblos de indios de Yucatán para vender a los mayas, por el precio de 10 tostones, copias de una provisión que prohibía que los religiosos castigaran a los indios. Además, el español no se contentaba con vender el documento escrito, sino que brindaba una interpretación oral del mismo a los mayas, dándoles a entender de palabra cosas "muy diferentes de lo que la nuestra dicha real provisión contenía". ${ }^{49}$ No queda dudas de que Rodrigo Fránquez procuraba tanto lucrar, aprovechándose del deseo de los indígenas de emanciparse de la tutela de los franciscanos, como desprestigiar a los religiosos y debilitar la autoridad que éstos ejercían sobre los mayas. ${ }^{50}$ Para la Real Audiencia de México, ante la cual el defensor Francisco Palomino denunció este negocio en 1576, el asunto era doblemente condenable, puesto que estaba prohibido vender copias de reales provisiones sin autorización y que la difusión del contenido del citado documento mermaba el prestigio de los frailes y perturbaba la evangelización de los mayas. Según la Audiencia, la actuación de Rodrigo Fránquez "había sido causa de que ellos [los indios] ya no acudiesen a la doctrina ni al sermón con el cuidado que solían hacer y había sido perturbación de la doctrina cristiana". ${ }^{51}$ Este incidente demuestra que, en la encarnizaba batalla por controlar a los pueblos de indios de Yucatán, la circulación y la manipulación de la informa-

${ }^{48}$ Información de Francisco Palomino para que se revoque cierta cédula y se le vuelva el oficio de defensor de los indios, Mérida, 1572. AGI, México 99, R. 1.

49 Provisión de la Real Audiencia de México a favor de Francisco Palomino y en contra de Jerónimo de Castro, Juan de Sanabria, Diego Briceño, Rodrigo Fránquez, Gómez de Castrillo y Don Carlos de Arellano, México, 22 de agosto de 1576. AGI, México 101, R. 3.

${ }_{50}$ Sobre la coerción ejercida por los franciscanos en las comunidades indígenas violencia franciscana, véase Clendinnen, "Indians" (nota 29), pp. 27-48.

51 Provisión de la Real Audiencia de México, México, 22 de agosto de 1576, AGI, México 101, R. 3. 
ción legal desempeñó un destacado papel. Pero también revela que los mayas participaron en esta lucha y que estaban incluso dispuestos a realizar una significativa inversión financiera conseguir copias de textos legales. ${ }^{52}$

De hecho, no fue la única vez que los españoles trataron de aprovecharse del deseo de los indígenas por conseguir y conservar información oficial. Así, pues, en 1580 el defensor Francisco Palomino denunció que el corregidor de Mérida y Concal, Juan López de Maya, vendía a los mayas todo tipo de escritos, especialmente copias de licencias para tener caballos o títulos de propiedad de la tierra. Según la cédula real por la que el Consejo de Indias mandó suspender a aquellos oficiales, el citado corregidor lucraba dando a los indios "licencias y mandamientos para tener caballos y confirmándoles las tierras y estancias que tienen y hubieron de sus padres y pasados para el mismo efecto, teniendo para ello por su escribano a un alguacil y naguatato a un Diego de Vargas". ${ }^{33}$ Tan sólo tres años después, el oidor y visitador de Yucatán, Diego García de Palacio, estipuló en sus ordenanzas para pueblos de indios que, para confirmar las elecciones de los gobernadores mayas, las máximas autoridades de la provincia no pudiesen cobrar a las comunidades indígenas cantidades superiores a doce reales. ${ }^{54}$ Todo ello sugiere que existió un verdadero mercado del documento legal en los pueblos de indios, mercado del que no fueron excluidos los títulos falsos, ya fueran éstos adquiridos de forma inocente o en pleno conocimiento de causa por los mayas, tema que merecería una investigación más profunda. ${ }^{55} \mathrm{~A}$ este respecto, cabe recordar que en 1561 un sacristán indígena de Zacatecas robó libros prohibidos, que el vicario había recogido para mandarlos a la ciudad de Guadalajara, y que los vendió a otros indígenas. ${ }^{56}$ Asimismo, David Távarez señala que varios textos rituales circulaban en "comunida-

${ }^{52}$ Sobre la inversión financiera que realizaron las comunidades andinas para conseguir justicia, véase José Carlos de la Puente Luna, "That Which Belongs to All. Khipus, Community, and Indigenous Legal Activism in the Early Colonial Andes": The Americas 72:1 (2015), pp. 19-59.

${ }^{53}$ Cédula al gobernador de Yucatán para que quite los corregidores de indios y haga justicia de agravios, 11 de noviembre de 1580, en Gabriela Solís Robleda/Pedro Bracamonte y Sosa, Cedulario de la dominación española en Yucatán. Siglo XVI (Mérida 2011), p. 383.

54 Ordenanzas que el doctor Palacio manda guardar entre los naturales de Yucatán, Mérida, 1583, en García Bernal, "García de Palacio" (nota 45), p. 8.

${ }^{55}$ Sobre la falsificación de documentos legales, véase Rafael Diego-Fernández Sotelo, "Falsificación del sello y reales cédulas de Felipe $\mathrm{V}$ en tiempos del marqués de Casa Fuerte (Nueva España 1720-1731)": Revista de Humanidades 22 (2014). En línea, http://www. revistadehumanidades.com/articulos/74-falsificacion-del-sello-y-reales-cedulas-de-felipe-v-en-tiempos-del-marques-de-casa-fuerte-nueva-espana-1720-1731 [19-06-2015].

${ }^{56}$ Francisco Fernández del Castillo (comp.), Libros y libreros en el siglo XVI (México 1982), pp. 38-44. 
des novohispanas de lectores indígenas" en el siglo XVII y que no era raro que vecinos letrados compraran copias de los mismos por cantidades que podían llegar a un peso. ${ }^{57}$

En estas circunstancias, no sorprende que existieran archivos en los pueblos de indios de Yucatán..$^{58}$ El Códice de Calkini narra, por ejemplo, cómo en el siglo XVI algunos principales de aquella comunidad se fueron hasta el pueblo de Maní para "buscar el mapa de los pueblos en el gran archivo que tienen [elaborado] por don Francisco Montejo Xiu". Según Tsubasa Okoshi Harada, el autor se refería a la "Memoria de la distribución de los montes" que realizó este cacique maya en el siglo XVI. ${ }^{59}$ Pero resulta aún más interesante observar que tanto la Memoria, como otros documentos legales elaborados a lo largo del periodo colonial fueron conservados hasta principios del siglo XX por las comunidades mayas y recibió el nombre de Papeles de los Xiu de Yaxá. ${ }^{60}$ En realidad, estos compendios legales son la prueba de la actividad de almacenamiento y conservación de información jurídica llevada a cabo en los pueblos mayas desde principios del siglo XVI. La conciencia de la necesaria conservación de lo escrito aparece en la Memoria, presentada como "documento escrito de lo sucedido [...] para que fuera recordado y sabido por aquellos que vengan lo que será provechoso en tiempos venidores". ${ }^{61}$ De hecho, la elaboración de los títulos primordiales siguió la misma lógica, ya que sus autores solían insistir en este aspecto en expresiones como "Esto se asienta sobre el papel, sabed, mis hijos, mis nietos, esto que pasamos a disponer, no nos olvidéis" o "Mirad este papel que pasamos a poner, ya vienen los españoles no se les enseñéis". ${ }^{62}$

${ }^{57}$ David Eduardo Tavárez, "La idolatría letrada. Un análisis comparativo de textos clandestinos rituales y devocionales en comunidades nahuas y zapotecas, 1613-1654": Historia Mexicana 49:2 (1999), pp. 197-252, aquí: p. 238.

${ }^{58}$ Véase Caroline Cunill, "Archivos mayas y la construcción de una memoria legal en Yucatán. Siglo XVI": Los reinos de las Indias en el Nuevo Mundo (2015), en línea, http:// losreinosdelasindias.hypotheses.org/885 [19-06-2015].

${ }^{59}$ Códice de Calkini, introducción, traducción y notas de Tsubasa Okoshi Harada (México 2009), p. 92. Cabe notar que en el texto maya la palabra archivo aparece en castellano, lo que sugiere que se trata de trasplante cultural de origen hispano.

${ }^{60}$ Véanse Tsubasa Okoshi Harada, "Otra lectura de la 'Memoria de la distribución de los montes, 1557' de los Papeles de los Xiu de Yaxá, Yucatán": Alfredo Barrera Rubio/Ruth Gubler (eds.), Los Mayas de ayer y hoy, vol. I (Mérida 2006) I, p. 778-791. Sergio Quezada/ Tsubasa Okoshi Harada, Los papeles de los Xiu de Yaxá, Yucatán (México 2001).

${ }^{61}$ Ibidem, p. 15.

${ }^{62}$ Margarita Menegus Bornemann, "Los títulos primordiales de los pueblos de indios": Margarita Menegus Bornemann (ed.), Dos décadas de investigaciones en historia económica. Homenaje a Carlos Sempat Assadourian (México 1999), pp. 137-161, aquí: pp. 152 y 154. 
Para entender esta valoración de lo escrito, tal vez sea oportuno recordar que en el sistema de justicia prehispánico los indios "no tuvieron costumbre de escribir cosas [referid]as ni cartas misivas y para los pleitos serví[an ... $\mathrm{mu}$ ]chos procuradores que siempre asistían [a] ...ssava entre ellos quedaba por rata". Esta diferencia con el sistema colonial, en la que insistió el maya Gaspar Antonio Chi en 1582, tal vez pueda explicar que, en el proceso de adaptación al orden hispano, los mayas otorgaran tanta importancia al documento escrito. ${ }^{63}$ Este fenómeno es comparable con lo que observa Johanne Rappaport en los Andes del norte, donde los indígenas atribuyeron un valor casi sagrado al sello real. ${ }^{64}$ También conviene subrayar que en Yucatán la alfabetización de los mayas se puso en marcha rápidamente, de modo que en las escuelas de los franciscanos se formó buena de parte de quienes pronto fungirían como escribanos en los cabildos indígenas o como fiscales en las iglesias. ${ }^{65}$ Además, la actividad archivística de los notarios indígenas fue reglamentada y hasta alentada por las autoridades hispanas. Así lo sugieren varias disposiciones de las ordenanzas para pueblos de indios elaboradas por el visitador Diego García de Palacio en 1583, donde se estipuló que los cabildantes "escribirán en su libro de cabildo como los eligen y nombran [a los gobernadores] y [...] enviarán ante el gobernador de estas provincias la dicha elección". Asimismo, cada sábado se juntarían el gobernador, regidores y principales para "leer estas ordenanzas para que todas las sepan y entiendan" ${ }^{66}$ Resulta acertada, por tanto, la expresión Making Indigenous Archives, utilizada por Kathryn Burns para referirse a la creación de archivos en los pueblos de indios del Perú, más allá de los límites estrictos de la "ciudad letrada" descrita por Ángel Rama. La autora insiste en el papel que desempeñaron en este proceso los escribanos presentes en los cabildos indígenas, también llamados Quilcaycamayoq o "guardianes de papeles" en Perú. ${ }^{67}$

${ }^{63}$ Matthias Strecker/Jorge Artiega, "Relación de algunas costumbres (1582) de Gaspar Antonio Chi": Estudios de Historia Novohispana 6 (1978), pp. 89-107, aquí: p. 99. Sobre Gaspar Antonio, véase Thomas Hillerkuss, "Los méritos y servicios de un maya yucateco principal del siglo XVI y la historia de sus probanzas y mercedes": Revista de Historia Novohispana 13 (1993), pp. 9-39.

${ }^{64}$ Joanne Rappaport, "Between Images and Writings. The Ritual of the King's Quillca": Colonial Latin American Review 7:1 (1998), pp. 7-32.

${ }^{65}$ Cunill, "Alfabetización" (nota 41), pp. 163-192.

${ }^{66}$ Ordenanzas que el doctor Palacio manda guardar entre los naturales de Yucatán, Mérida, 1583, en García Bernal, "García de Palacio" (nota 45), p. 8.

${ }^{67}$ Kathryn Burns, "Making Indigenous Archives. The Quilcaycamayoq in Colonial Cuzco": Ramos/Yannakakis (eds.), Indigenous Intellectuals (nota 38), pp. 237-259. Ángel Rama, The lettered City (Durham 1996 [1984]). Joanne Rappaport/Tom Cummins ampliaron el concepto de "ciudad letrada", al incluir en él a los indígenas, en Beyond the Lettered City. Indigenous Literacies in the Andes (Durham 2012). 
Todo ello muestra el continuo interés que manifestaron los indígenas para conseguir y conservar documentos legales. $Y$ es que la conformación de una cultura jurídica nunca fue un juego vacuo, sino que en ella se trabaron muchos intereses, de modo que se desataron fuertes tensiones en torno a esta cuestión. Por consiguiente, todos los sectores de la sociedad colonial, mayas, religiosos, defensores de indios, encomenderos, cabildos españoles y gobernadores de Yucatán, estuvieron involucrados en esta lucha. En 1572 el defensor Francisco Palomino escribió a los caciques mayas para decirles "cómo, por mandado de Vuestra Majestad, venía a esta tierra por su protector y defensor para el efecto que contiene la provisión de mi cargo en que se me ordena y manda lo que debo hacer en el uso y ejercicio de él". ${ }^{68}$ Pretendía que los mayas conocieran la naturaleza de su función y que reconocieran la legitimidad que le brindaba esta cédula real. En aquella ocasión el defensor también pidió a los caciques información escrita sobre los abusos sufridos en el servicio personal, ya que sabía que "se les había pedido y sacado más servicio personal [...] de lo que buenamente podían dar" y quería "la memoria de ello para asentarlo en un libro y ocurrir ante la justicia para que remediase el exceso". ${ }^{69}$ No obstante, el cabildo de la villa de Valladolid, integrado en su mayoría por encomenderos, interpuso una querella criminal en contra de Francisco Palomino para que el gobernador Diego de Santillán prohibiera que el defensor pudiese dirigirse directamente a los mayas para brindarles y/o solicitarles información legal. ${ }^{70} \mathrm{~A}$ su vez, Francisco Palomino argumentó que, si no podía comunicarse con los mayas, su misión resultaría menoscabada e insistió en la supuesta minoría de los indios para justificar el papel activo que debía desempeñar el titular del cargo de defensor en la recolección de información que permitiera emprender acciones legales. ${ }^{71}$

Este acto de comunicación con los caciques yucatecos no fue un evento aislado en la historia de la provincia, ya que dos años más tarde el defensor Diego Briceño "escribió a todos los caciques de la tierra" para informarles de que su predecesor Francisco Palomino estaba preso y, "si les había hecho algún agravio o tomado sus haciendas, que lo dijesen". Según Francisco Palomino, el motivo de esta campaña en su contra radicaba en la lucha que llevó a cabo para que los encomenderos sufragaran los gastos de doctrina en

\footnotetext{
${ }^{68}$ Carta de Francisco Palomino al rey, Mérida, 2 de octubre de 1572. AGI, México 99, R. 3.

${ }^{69}$ Ibidem. Sobre el servicio personal, véase Manuela Cristina García Bernal, "Los servicios personales en el Yucatán del siglo XVI": Estudios sobre politica indigenista española en América. Terceras Jornadas Americanistas de la Universidad de Valladolid 2 (1976), pp. 269-279.

${ }^{70}$ Sobre la composición social de los cabildos de Yucatán, véase Victoria González Muñoz, Cabildos y grupos de poder en Yúcatán. Siglo XVII (Sevilla 1994).

${ }^{71}$ Carta de Francisco Palomino al rey, Mérida, 2 de octubre de 1572. AGI, México 99, R. 3.
} 
sus pueblos. Al comprobar que las justicias de Yucatán se negaban a aplicar las leyes vigentes al respecto, el defensor se había dirigido a la Real Audiencia de México, que mandó una provisión exigiendo que el gobernador hiciera cumplir las disposiciones reales. ${ }^{72}$ Pero el gobernador Diego de Santillán, que compartía importantes intereses con la clase encomendera, mandó encarcelar al defensor, nombró en su lugar a Diego Briceño y trató de conseguir testimonios mayas en contra de Francisco Palomino para justificar su encarcelamiento. No obstante, éste pronto organizó una campaña de contra-información con el apoyo de los franciscanos, quienes se mostraban favorables a que los encomenderos pagaran la doctrina. Por consiguiente, los religiosos "en sus guardianías hablaron a todos los caciques juntos y vocalmente, delante de muchos españoles, les dijeron y dieron a entender que mirasen, como personas libres que eran, dijesen en Dios y en su conciencia si era verdad lo que de mí se decía". Además, los franciscanos animaron a los caciques a que redactaran un documento escrito sobre la probidad de Francisco Palomino. ${ }^{73}$ Para contrarrestar el fenómeno, el gobernador Santillán se apresuró en nombrar a "jueces de comisión" que viajaron a los pueblos para encarcelar a los mayas y poner multas a los españoles quienes habían declarado a favor de Francisco Palomino. ${ }^{74}$

No cabe duda de que tanto los defensores, como los religiosos ocuparon un destacado lugar en la cadena de información que vinculaba a la población maya con la clase política local y, en última instancia, con el Consejo de Indias. Y es que los franciscanos no sólo eran grandes conocedores de la lengua maya, sino que pronto se repartieron por toda la provincia gracias al sistema de guardianías que, según William Hanks, funcionaron como estructuras intermediarias entre los pueblos de indios y el gobierno provincial de Yucatán. ${ }^{75}$ También queda patente la importancia estratégica que revestía la comunicación con los mayas, puesto que sus testimonios, orales y escritos, tenían un peso decisivo en la mayoría de los procedimientos legales que se llevaban a cabo en América. ${ }^{76}$ No por nada en el interrogato-

${ }^{72}$ Carta de Francisco Palomino al rey, Mérida, 31 de abril de 1574. AGI, México 99, R. 6. Sobre la pelea acerca del pago de los gastos de doctrina en Yucatán, véase Cunill, Defensores (nota 33), pp. 250-252.

${ }^{73}$ Carta de Francisco Palomino al rey, Mérida, 31 de abril de 1574. AGI, México 99, R. 6.

${ }^{74} \mathrm{Ibidem}$. En la misma carta Francisco Palomino señala que en la residencia que el gobernador Francisco Velázquez de Gijón le tomó a Diego de Santillán, lo condenó a que pagara "todos los gastos que hizo a los indios por la dicha declaración que hicieron en mi favor".

${ }^{75}$ William F. Hanks, "Reducción and the Reforming of the Social Landscape in Colonial Yucatan": Alain Breton/Aurore Monod-Becquelin/Mario Humberto Ruz (eds.), Espacios mayas. Usos, representaciones, creencias (México 2003), pp. 161-180, aquí: p. 170.

${ }^{76}$ Sobre el valor jurídico de los códices indígenas, por ejemplo, véase Ethelia Ruiz Medrano/Perla Valle, "Los colores de la justicia. Códices jurídicos del siglo XVI en la 
rio de la pesquisa secreta del juicio de residencia que se tomó al gobernador Luis Céspedes de Oviedo en 1571 se les preguntó a los testigos mayas y españoles si sabían si éste se habían "servido de los dichos indios enviándoles con cartas y mensajeros de unos lugares a otros y con dádivas y presentes a quien se les antojaba cargados con cargas excesivas y largos caminos". ${ }^{77}$ Otro elemento relevante, que también aparece a lo largo del estudio, es la frecuente combinación que hacían los actores históricos, ya fueron éstos representantes de la Corona española, encomenderos o religiosos, entre comunicación escrita y oral, con las posibles distorsiones que la transcripción oral de los documentos escritos podía suponer. Evidentemente, la circulación oral de la información legal alcanzaba a un público más extenso, esto es, a los mayas no alfabetizados, lo que permitía resquebrajar el monopolio del conocimiento legal que pudiera tener la élite indígena. Aquel reto sale a la luz en otra contienda de raigambre político-económica en la que estuvo involucrado, una vez más, el defensor de indios Francisco Palomino.

En la década de 1570 la explotación de añil se encontraba en plena expansión en Yucatán, ya que esta materia tintórea azul se exportaba a Europa para satisfacer la creciente demanda de la industria textil. Así, pues, según Manuela Cristina García Bernal, en 1576 la producción alcanzaba las 600 arrobas y en 1577 los españoles habían establecido 48 ingenios "con un costo aproximado de 2.000 y 3.000 pesos cada uno, pero también con un rendimiento elevado". ${ }^{78}$ Esta situación dio lugar a numerosos abusos, al aumentar los encomenderos los niveles de compulsión en la uso del trabajo indígena. Ahora bien, en su lucha para poner fin a la explotación de los mayas el defensor Francisco Palomino decidió informar a los indígenas de una cédula promulgada en 1575 , por la que la Corona española prohibía que los indios sirviesen en la granjería del añil si no fuese de su propia voluntad y recibiendo el debido salario. Por consiguiente, el defensor envió a todos los caciques, por mediación de los religiosos, copias de este documento. Por otro lado, recorrió personalmente algunos pueblos de la provincia con el fin de dar a conocer oralmente a los mayas el contenido de la cédula. ${ }^{79}$ Según Francisco Palomino, el uso de la comunicación oral estaba justifi-

Biblioteca Nacional de Francia": Journal de la société des Américanistes 84:2 (1998), pp. 228-235.

${ }^{77}$ Pregunta 45 del interrogatorio presentado en la pesquisa secreta, en la residencia de don Luis Céspedes de Oviedo, 1571. AGI, Justicia 250, fol. 18v.

${ }^{78}$ Manuela Cristina García Bernal, Población y encomienda en Yucatán bajo los Austrias (Sevilla 1978), p. 450.

${ }^{79}$ Memorial del defensor Francisco Palomino al rey, Mérida, 20 de febrero de 1576. AGI, México 101, R. 2. Francisco Palomino se refería a la cédula real al gobernador de Yucatán para que no permita aue los encomenderns aoravión a Inc indins on $n 1$. 
cado por la necesidad de evitar la mediación de los caciques, pues sospechaba que éstos se dejaban corromper por los encomenderos con "vino y otras cosas" y que, "a trueque de las dichas dádivas, dicen a los dichos macehuales [indios del común] cómo el gobernador se lo manda [dar indios de servicios] con pena y que ellos no pueden más que vayan porque, de otra manera, los llevarán a ellos a la cárcel y así sacan cuántos indios quieren" ${ }^{80}$ Pero la situación era más compleja, dado que el mismo defensor reportó que algunos españoles engañaban a los mayas, usando de "muchas cautelas con ellos, porque de una carta vieja que lleven en las manos darán a entender a los indios que es cédula de Vuestra Majestad o mandamiento del gobernador en que manda le den toda la gente del pueblo que le vayan a servir". ${ }^{81}$ Así, parte del problema también parecía radicar en la supuesta ignorancia de los indígenas y la falta de escrúpulos de los colonos, que entraron en el intrincado juego de la comunicación con los mayas con documentos falsos. Pero también tenía mucho que ver, en realidad, con la coerción, ya que, según Francisco Palomino, los indios "todo lo creen y más si ven una vara de justicia en el pueblo y les dicen que si no cumplen lo que les piden los han de llevar a la cárcel y tener presos, darán sus mujeres e hijas porque no los lleven". ${ }^{82}$ En consecuencia, se puede argüir que en la sociedad colonial la constante tensión entre la circulación de la ley y la presión de un sistema coercitivo y desigual conformaba un espacio movedizo en el que pedir y conseguir justicia no era fácil.

\section{Consideraciones finales}

En cualquier época, la circulación de la información ha tenido fuertes incidencias en los procesos legales y, por ende, en los equilibrios de poder. En la América colonial el envío de informes influía en la promulgación de las leyes y, a su vez, la correcta recepción de las leyes garantizaba la eficaz defensa de los intereses en juego. Por otra parte, los testimonios también

Lorenzo, 4 de enero de 1575, en Solís Robleda/Bracamonte y Sosa, Cedulario (nota 53), pp. 290-291.

${ }^{80}$ Memorial del defensor Francisco Palomino al rey, Mérida, 20 de febrero de 1576. AGI, México 101, R. 2. Las dudas del defensor sobre la honestidad de los caciques eran compartidas por las autoridades coloniales, que sospechaban que éstos pedian a sus macehuales más tributo del que estaba tasado para quedarse con lo que sobraba. Por consiguiente, uno de los objetivos de las tasaciones consistió en "que los súbditos sepan lo que han de dar" a sus caciques y principales.

${ }^{81}$ Ibidem.

m... 
revistieron un peso determinante en la resolución tanto de los juicios civiles y criminales, como de los juicios de residencia que se tomaban a los oficiales reales. Y, al ser declarados vasallos libres del rey de España y al reconocerse el valor legal de sus testimonios, los indígenas participaron activamente en estos mecanismos. Así, la Corona española se esforzó por fomentar la creación de una cultura jurídica entre los indígenas y éstos hicieron lo posible para conocer, adquirir y conservar textos legales. Todo ello explica por qué los naturales manifestaron desde fechas tempranas un amplio conocimiento de los conceptos legales que se iban forjando en el continente. Pero la magnitud de los intereses en juego empujó a que todos los sectores de la sociedad colonial tratasen de inmiscuirse en estos procesos. El estudio revela el empeño manifestado por defensores, religiosos, encomenderos y hasta por los gobernadores de Yucatán por favorecer o, al contrario, obstaculizar la circulación de la información jurídica entre los mayas. De este modo, mucha documentación legal llegó hasta en los pueblos más alejados de la península yucateca, donde las autoridades indígenas confeccionaron auténticos archivos. Sin embargo, el último escollo que encontraron, tanto la circulación de la información como la producción del derecho, fueron el engaño y la coerción. Algunos españoles no dudaron en vender documentación falsa a los mayas, algunos caciques en esconder órdenes reales a los indios del común y algunos gobernadores en nombrar a jueces de comisión para castigar a quienes no habían hecho declaraciones a su favor. 